\title{
Tube shunt coverage with gamma-irradiated cornea allograft (VisionGraft)
}

\author{
This article was published in the following Dove Press journal: \\ Clinical Ophthalmology \\ 28 April 2015 \\ Number of times this article has been viewed
}

\section{Feyzahan Ekici \\ Marlene R Moster \\ Victor Cvintal \\ Wanda D Hu \\ Michael Waisbourd}

Glaucoma Research Center, Wills Eye Hospital, Philadelphia, PA, USA
Correspondence: Feyzahan Ekici Glaucoma Research Center, Wills Eye Hospital, 840 Walnut Street, Suite I I40, Philadelphia, PA 19107, USA

Tel +l 2159283200

$\mathrm{Fax}+\mathrm{I} 2159280166$

Email feyzahan@gmail.com
Purpose: To investigate the clinical outcomes of tube shunt coverage using sterile gamma-irradiated cornea allograft.

Patients and methods: The Wills Eye Hospital Glaucoma Research Center retrospectively reviewed the medical records of 165 patients who underwent glaucoma tube shunt procedures using sterile gamma-irradiated cornea allograft (VisionGraft) between December 2012 and November 2013. Demographic characteristics, type of tube shunt, and position were noted. Complications were recorded at 1 day; 1 week; 1, 3, 6, and 12 months; and on the final postoperative visit.

Results: One hundred and sixty-nine eyes of 165 patients were included. The mean follow-up time was $4.8 \pm 3.5$ (ranging from 1 to 16 ) months. There was no evidence of immunological reaction, infection, or exposure in 166 eyes (98.2\%). Three eyes (1.8\%) experienced graft or tube exposure within the first 3 postoperative months. Two of the cases had underlying diseases: bullous pemphigoid and chronic allergic conjunctivitis.

Conclusion: Coverage of tube shunts using gamma-irradiated cornea allograft had a low exposure rate and was well tolerated. The graft can be stored long term at room temperature and has an excellent postoperative cosmetic appearance.

Keywords: aqueous shunts, gamma-irradiated cornea allograft, glaucoma drainage device, tube shunt surgery

\section{Introduction}

Tube shunts have been widely used in the treatment of eyes with complicated glaucoma. ${ }^{1}$ Although tube shunts were introduced primarily for refractory cases, recently they are increasingly used as a primary surgical procedure. ${ }^{2}$

Tube shunt surgery is associated with complications including tube or plate exposure, tube migration, and infection. ${ }^{3}$ Tube-related exposure, which is a significant risk factor for the development of postoperative endophthalmitis, requires prompt surgical intervention. ${ }^{4}$ Numerous materials including pericardium, ${ }^{5}$ human sclera,${ }^{6}$ dura, ${ }^{7}$ fascia lata, ${ }^{8}$ porcine intestinal submucosa, ${ }^{9}$ and amniotic membrane ${ }^{10}$ have been used to decrease the exposure rates of tube shunt surgeries. Each material has its own advantages and disadvantages regarding success rates, storage conditions, availability, patient comfort, and cosmetic appearance.

Recently, several types of processed donor cornea tissue have been used in primary coverage of tube shunts, repair of exposed implant, and repair of filtering bleb leaks. ${ }^{11-14}$ Gamma irradiation is an effective method for the sterilization of donor tissues. By avoiding the risk of bacterial, fungal, and virus transmission it offers more safety when compared to fresh corneas. ${ }^{15}$ In recent pilot studies, gamma-irradiated sterile cornea allograft has been reported effective and safe as a coverage material for glaucoma tube shunt surgery in a limited number of patients. ${ }^{16,17}$ 
In this study, we report our outcomes of using gammairradiated cornea allograft as a coverage material for glaucoma tube shunt surgeries. To the best of our knowledge, this current study is the largest study to date reporting the outcomes of tube shunt coverage using this patch graft.

\section{Patients and methods}

After the approval by the Institutional Review Board at the Wills Eye Hospital, a retrospective chart review was performed. All research methods were in compliance with the Declaration of Helsinki.

A total of 185 eyes underwent a primary or secondary tube shunt surgery using sterile gamma-irradiated cornea allograft (VisionGraft, Tissue Banks International Inc., Baltimore, MD, USA) between December 2012 and November 2013. Charts were included from 169 eyes of 165 patients who had complete information and follow-up data for at least 1 month. Preoperative data collected included age, sex, race, and type of glaucoma. Intraoperative data collected included type of tube, tube position, and type of surgery. Complications were recorded at 1 day; 1 week; $1,3,6$, and 12 months; and final postoperative visit. Primary outcome was the ability of the allograft to remain stable and biocompatible postoperatively. Stability and biocompatibility were measured clinically by the integrity of the overlying conjunctiva and the allograft itself, signs of inflammation, and the need for surgical revision.

Sterile gamma-irradiated cornea allograft is obtained from a medically qualified donor. This procedure is committed to tissue safety and maintains compliance with appropriate and required regulatory agencies including the Eye Bank Association of America, the American Association of Tissue Banks, and the US Food and Drug Administration. ${ }^{18}$ The allografts are sterilized using gamma radiation. The allograft is stored at room temperature for up to 18 months in a box containing a vial of sterile $5 \mathrm{~mL} 25 \%$ human albumin.

For this study we used $9 \mathrm{~mm}$ split-thickness half-moon cornea allograft (Catalog number: CO300AL-90) (Figure 1). During the surgery, the allograft was transported to the surgical table, removed from the sterile vial and rinsed with balanced salt solution before use. All allografts were implanted over the tube, under the conjunctiva and sutured to the sclera with several 10-0 nylon sutures (Figure 2).

\section{Results}

A total of 169 eyes from 165 patients ( 71 male, 94 female) were included in this study. Mean age was $69.5 \pm 16.5$ (ranging from 15 to 99 ) years. Patients' demographic data are

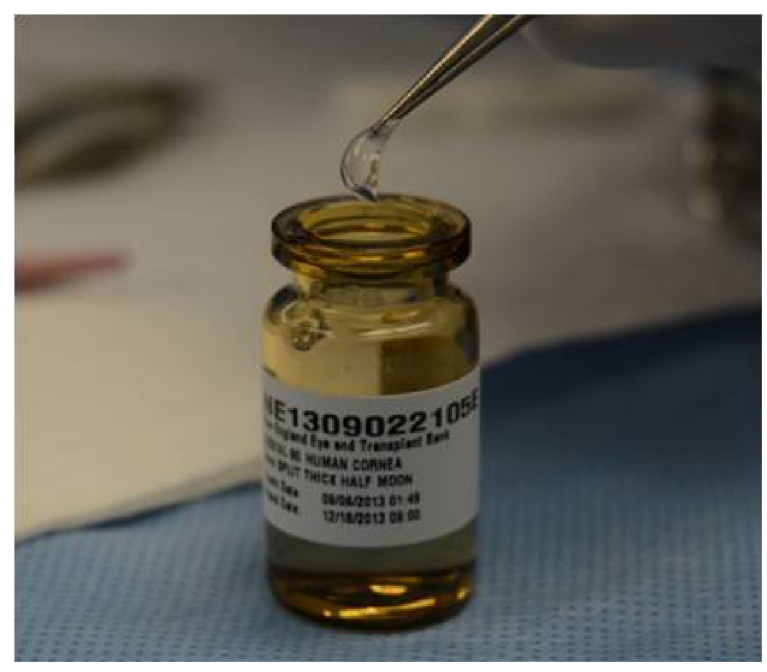

Figure I Gamma-irradiated cornea allograft.

summarized in Table 1. Mean follow-up time was $4.8 \pm 3.5$ (ranging from 1 to 16) months.

Cornea allografts were used for primary $(87.5 \%)$ and secondary $(7.7 \%)$ surgeries as well as for the repair of exposure $(4.7 \%)$. The majority of tube shunts were implanted in the superotemporal quadrant (72.7\%). Thirty-three eyes (19.5\%) had tube shunts in the inferior quadrants. Clinical characteristics are summarized in Table 2.

The vast majority of the allografts, 166/169 (98.2\%), were stable during the follow-up period, with no evidence of immunological reaction, infection, or exposure. Three eyes (1.8\%) experienced exposure of the graft or tube within the first 3 postoperative months and all these three patients had tubes superotemporally located. Two graft exposures occurred in the first postoperative month, and both cases had underlying diseases: chronic allergic conjunctivitis with history of eye rubbing and bullous pemphigoid. The third patient had tube erosion that was noticed during the third

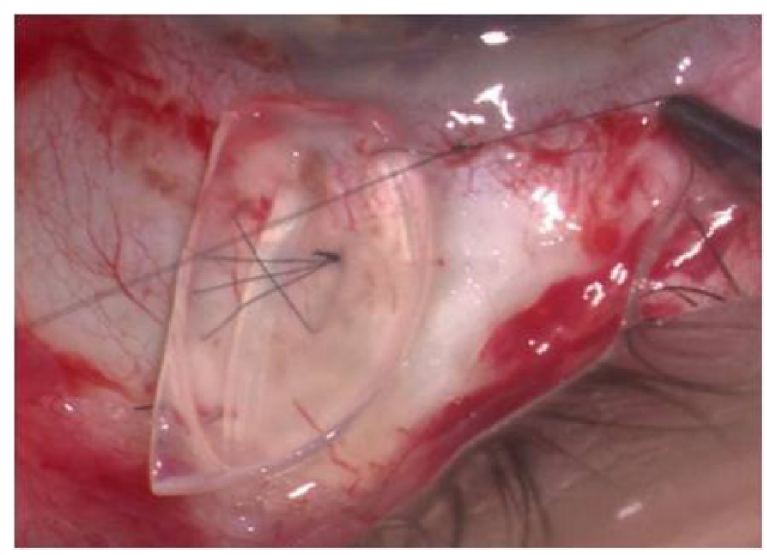

Figure 2 Intraoperative view of the gamma-irradiated cornea allograft. 
Table I Demographic characteristics of the patients reviewed in the study

\begin{tabular}{ll}
\hline Number of patients, $\mathrm{n}$ (eyes) & 165 (I69 eyes) \\
Age (years), mean \pm SD & $69.5 \pm 16.5$ \\
Sex, $\mathrm{n}(\%)$ & \\
Male & $71(43 \%)$ \\
Female & $94(57 \%)$ \\
Race & \\
White & $112(67.8 \%)$ \\
African-American & $38(23 \%)$ \\
Hispanic & $11(6.7 \%)$ \\
Asian & $2(1.2 \%)$ \\
Other & $2(1.2 \%)$ \\
Diagnosis, $n$ (\%) & \\
POAG & $97(57.3 \%)$ \\
CACG & $16(9.5 \%)$ \\
PXFG & $15(8.9 \%)$ \\
PG & $7(4.1 \%)$ \\
Other & $34(2.8 \%)$ \\
Follow-up time (months), mean \pm SD & $4.8 \pm 3.5$ \\
\hline
\end{tabular}

Abbreviations: POAG, primary open angle glaucoma; CACG, chronic angle closure glaucoma; PXFG, pseudoexfoliative glaucoma; PG, pigmentary glaucoma; $\mathrm{SD}$, standard deviation.

postoperative month. All three cases underwent tube revision surgery and were successfully repaired.

\section{Discussion}

Tube shunt surgery for glaucoma is gaining popularity and is being increasingly used as a primary glaucoma surgery. ${ }^{2}$ Erosion of the conjunctiva overlying the tube shunt and tube exposure is a complication that significantly increases the risk of endophthalmitis. ${ }^{4}$ Coverage of the tube shunt is necessary both during primary implantation and for the repair of an eroded tube to prevent further conjunctival erosion and erosion-related infection and inflammation. In this study, we

Table 2 Clinical characteristics of the surgeries performed

\begin{tabular}{ll}
\hline & $\mathbf{n}=\mathbf{l} 69$ eyes \\
\hline Type of tube shunt, $\mathrm{n}(\%)$ & \\
Ahmed M4 & $86(50.8 \%)$ \\
Baerveldt 350 & $47(27.8 \%)$ \\
Ahmed FP7 & $22(13.1 \%)$ \\
Baerveldt 250 & $12(7.1 \%)$ \\
Schocket procedure & $2(1.1 \%)$ \\
Tube position, $\mathrm{n}(\%)$ & $123(72.7 \%)$ \\
$\quad$ Superotemporal & $18(10.6 \%)$ \\
Inferotemporal & $15(8.9 \%)$ \\
Inferonasal & $13(7.7 \%)$ \\
$\quad$ Superonasal & \\
Type of surgery, $\mathrm{n}(\%)$ & $148(87.5 \%)$ \\
Primary tube shunt & $13(7.7 \%)$ \\
Second tube shunt & $8(4.7 \%)$ \\
Repair of exposure & \\
\hline
\end{tabular}

reviewed the outcomes of using a sterile gamma-irradiated cornea allograft to cover tube shunts. We found that cornea allografts were safe, effective, biocompatible, and stable for both primary implantations and secondary repair surgeries.

Traditionally, tube shunts were covered with scleral patch grafts and conjunctival erosion or exposure was found in $2 \%-3 \%$ of cases. ${ }^{19}$ Smith et al compared donor sclera, donor dura, and donor pericardium and none of the patch grafts used to cover tube shunts was superior to the others in preventing conjunctival erosion and exposure. ${ }^{20}$ More recently, different materials, such as processed cornea, porcine intestinal submucosa, and amniotic membrane have been used to cover tube shunts. These materials are readily prepared and commercially available for this specific purpose. Table 3 shows the rate of tube exposure for the different materials, ranging between $0 \%-16 \%$. $9,10,12,14,16,20-23$

Using corneal tissue as a patch graft to facilitate postoperative suture lysis was first described in $1996 .{ }^{11}$ Others have described the use of glycerol preserved or cryoprotected and frozen corneal tissues as a patch graft. ${ }^{12,14}$ Cryopreserved corneal patch grafts were well tolerated after the repair of exposed implants. ${ }^{12}$ A recently published study found the exposure rates of glycerol-preserved corneal patch grafts significantly lower than those seen with pericardium patch grafts. ${ }^{14}$

The use of gamma-irradiated cornea allograft has the advantages of decreased risk of disease transmission due to the sterilization process by gamma-irradiation, and shelf life of up to 2 years at room temperature. The graft material comes pre-cut in various shapes and does not require presurgical preparation. ${ }^{17}$ It has been suggested that the dense lamellar structure of the corneal tissue offers high tensile strength, rigidity, and relatively more resistance to melting when compared with the loose structure of other tissues such as sclera or pericardium. ${ }^{12,16}$ The clarity of the graft (Figure 3) allows postoperative procedures such as suture lysis and provides excellent postoperative cosmetic appearance, especially with inferiorly placed implants.

Two pilot studies found the gamma-irradiated cornea allograft to be effective and safe in tube shunt surgery with no exposures during the follow-up period. ${ }^{16,17}$ To the best of our knowledge, the current study is the largest study to date reporting the outcomes of tube shunt coverage using this patch graft. We found an exposure rate of $2 \%$ (three out of 169 eyes).

There are several studies in the literature identifying the risk factors for tube erosions. Prior or concomitant surgeries were found to induce conjunctival scarring and thinning leading 
Table 3 Rates of tube exposure for patch graft materials

\begin{tabular}{|c|c|c|c|c|c|}
\hline Author (year) & Tube coverage material & $\begin{array}{l}\text { Eyes } \\
(n)\end{array}$ & $\begin{array}{l}\text { Mean follow-up } \\
\text { time (months) }\end{array}$ & $\begin{array}{l}\text { Rate of } \\
\text { exposure (\%) }\end{array}$ & $\begin{array}{l}\text { Additional complications/ } \\
\text { comments }\end{array}$ \\
\hline Raviv et a|21 (1998) & Pericardium (Tutoplast) & 44 & 10.2 & None & Graft thinning in five eyes \\
\hline \multirow[t]{4}{*}{ Smith et $\mathrm{al}^{20}(2002)$} & Donor sclera & 23 & 66 & 4.3 & The differences between the \\
\hline & (EtoH-preserved) & & & & groups were not statistically \\
\hline & Dura (Tutoplast) & 18 & 47 & 5.6 & significant \\
\hline & Pericardium (Tutoplast) & 23 & 33 & None & \\
\hline \multirow[t]{2}{*}{ Singh et al' ${ }^{\prime 2}(2008)$} & Corneal patch graft & 8 & 36.3 & None & One eye developed a leaking fistula \\
\hline & (cryoprotected) & & & & \\
\hline \multirow{3}{*}{$\begin{array}{l}\text { Lankaranian et } \mathrm{al}^{22} \\
(2008)\end{array}$} & Pericardium (Tutoplast-single & 31 & 18.6 & 16 & Less erosions in the double \\
\hline & thickness) & & & & thickness group $(P=0.002)$ \\
\hline & $\begin{array}{l}\text { Pericardium (Tutoplast- } \\
\text { double thickness) }\end{array}$ & 59 & 21.1 & None & \\
\hline Anand et al ${ }^{10}(20 \mathrm{II})$ & Amniotic membrane & 42 & 22 & 2 & \\
\hline \multirow{3}{*}{$\begin{array}{l}\text { Wigton et al }{ }^{14} \\
(2012)\end{array}$} & Corneal patch graft & 161 & 14.6 & 1.9 & Less erosions in the glycerol- \\
\hline & (glycerol-preserved) & & & & preserved corneal patch graft group \\
\hline & Pericardium (Tutoplast) & 101 & II & 8.9 & $(P=0.012)$ \\
\hline Lawrence et al ${ }^{16}$ & Gamma-irradiated & 10 & 24 & None & \\
\hline$(2013)$ & cornea allograft (VisionGraft) & & & & \\
\hline \multirow[t]{2}{*}{ Nagi et al ${ }^{9}(20 \mid 3)$} & Porcine small intestinal & 42 & 15.2 & 10 & \\
\hline & submucosa (Kerasys) & & & & \\
\hline Trubnik et $\mathrm{a}^{23}(2013)$ & Pericardium (Tutoplast) & 339 & 24 & 6.1 & Tutoplast used for most eyes reviewed \\
\hline
\end{tabular}

to erosion. ${ }^{23-26}$ Additionally, diabetes, African-American or Hispanic ethnicity, neovascular glaucoma, previous glaucoma laser procedures, smoking and history of dry eye were also associated with erosions. . $3,25,26^{2}$

Patch graft melting and exposure may be related to several mechanisms: high grade immune mediated process with resultant rapid melting, mechanical processes and a low grade immune-mediated long-term atrophy. ${ }^{20}$ Lankaranian et al postulated that the frequent rubbing combined with mechanical actions of the upper lid may also lead to tube erosions. ${ }^{22}$ In this current study, two of the three patients who experienced tube erosions had an underlying cause: one had bullous pemphigoid and the other had chronic allergic conjunctivitis with a history

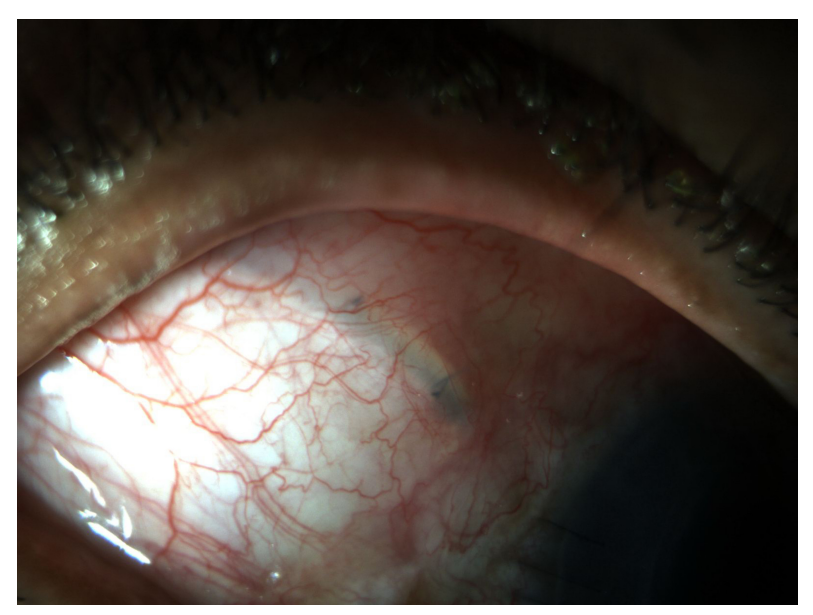

Figure 3 Postoperative view (month I) demonstrating excellent cosmetic appearance using the gamma-irradiated cornea allograft. of chronic eye rubbing. Bullous pemphigoid is a common autoimmune subepidermal blistering disease characterized by poor wound healing and chronic inflammation. ${ }^{27,28}$ Chronic allergic conjunctivitis is directly linked with increased tendency for inflammation, and it was suggested that prematurely loosened sutures following keratoplasty was associated with this condition. ${ }^{29}$ Moreover, eye rubbing secondary to allergic conjunctivitis may cause mechanical insult to the patch graft and contribute to the exposure as well.

The cost of the gamma-irradiated corneal allograft in our surgical center is approximately $10 \%$ higher compared with Tutoplast pericardium, Tutoplast dura, and porcine small intestinal patch grafts. When taking into consideration the total costs of the surgery, using gamma-irradiated cornea allograft increases the cost of the surgery by approximately $1 \%$ compared with other commercially available materials.

The primary weaknesses of our study is its retrospective, non-comparative nature and our short-term follow-up period. A larger prospective comparative study is needed to fully investigate the rate of exposures with this patch graft compared to other materials.

In conclusion, the gamma-irradiated cornea allograft was well tolerated in nearly all of our patients. There was no clinical evidence of graft-related infection and inflammation in any of the eyes. The gamma-irradiated cornea allograft is readily available, offers sterility advantages, as well as improved cosmesis due to its transparency. Gammairradiated cornea allograft may be an alternative coverage graft material for glaucoma tube shunt surgeries. 


\section{Disclosure}

The authors have no conflicts of interest to disclose.

\section{References}

1. Gedde SJ, Parrish RK 2nd, Budenz DL, Heuer DK. Update on aqueous shunts. Exp Eye Res. 2011;93(3):284-290.

2. Mosaed S. Update on aqueous shunts in glaucoma. Int Ophthalmol Clin. 2011;51(3):155-164.

3. Nguyen QH. Avoiding and managing complications of glaucoma drainage implants. Curr Opin Ophthalmol. 2004;15(2):147-150.

4. Al-Torbak AA, Al-Shahwan S, Al-Jadaan I, Al-Hommadi A, Edward DP. Endophthalmitis associated with the Ahmed glaucoma valve implant. Br J Ophthalmol. 2005;89(4):454-458.

5. Lama PJ, Fechtner RD. Tube erosion following insertion of a glaucoma drainage device with a pericardial patch graft. Arch Ophthalmol. 1999; 117(9):1243-1244.

6. Zeppa L, Romano MR, Capasso L, Tortori A, Majorana MA, Costagliola C. Sutureless human sclera donor patch graft for Ahmed glaucoma valve. Eur J Ophthalmol. 2010;20(3):546-551.

7. Brandt JD. Patch grafts of dehydrated cadaveric dura mater for tube-shunt glaucoma surgery. Arch Ophthalmol. 1993;111(10):1436-1439.

8. Gutierrez-DiazE, Montero-Rodriguez M, Mencia-GutierrezE, Cabello A, Monescillo J. Long-term persistence of fascia lata patch graft in glaucoma drainage device surgery. Eur J Ophthalmol. 2005;15(3): 412-414.

9. Nagi KS, Cumba RJ, Bell NP, et al. Short-Term Outcomes of KeraSys Patch Graft for Glaucoma Drainage Devices: A Case Series. J Ophthalmol. 2013;2013:784709.

10. Anand A, Sheha H, Teng CC, Liebmann JM, Ritch R, Tello C. Use of amniotic membrane graft in glaucoma shunt surgery. Ophthalmic Surg Lasers Imaging. 2011;42(3):184-189.

11. Rojanapongpun $P$, Ritch R. Clear corneal graft overlying the seton tube to facilitate laser suture lysis. Am J Ophthalmol. 1996;122(3):424-425.

12. Singh M, Chew PT, Tan D. Corneal patch graft repair of exposed glaucoma drainage implants. Cornea. 2008;27(10):1171-1173.

13. Mistlberger A, Biowski R, Grabner G. Repair of a late-onset filtering bleb leak using a corneal graft shaped with an excimer laser. Ophthalmic Surg Lasers. 2001;32(5):428-431.

14. Wigton E, C Swanner J, Joiner W, et al. Outcomes of Shunt Tube Coverage With Glycerol Preserved Cornea Versus Pericardium. J Glaucoma. 2014;23(4):258-261.

15. Miekka SI, Forng RY, Rohwer RG, et al. Inactivation of viral and prion pathogens by gamma-irradiation under conditions that maintain the integrity of human albumin. Vox Sang. 2003;84(1):36-44.
16. Lawrence SD, Netland PA. Gamma-irradiated cornea allograft for glaucoma surgery. J Glaucoma. 2013;22(5):355-357.

17. Daoud YJ, Smith R, Smith T, Akpek EK, Ward DE, Stark WJ. The intraoperative impression and postoperative outcomes of gamma-irradiated corneas in corneal and glaucoma patch surgery. Cornea. 2011;30(12): $1387-1391$.

18. Tissue Banks International [homepage on the Internet]. Accreditation and Licensure. Available from: http://www.tbionline.org/accreditationlicensure.php. Accessed 3 April, 2014.

19. Stewart WC, Kristoffersen CJ, Demos CM, Fsadni MG, Stewart JA. Incidence of conjunctival exposure following drainage device implantation in patients with glaucoma. Eur J Ophthalmol. 2010;20(1):124-130.

20. Smith MF, Doyle JW, Ticrney JW Jr. A comparison of glaucoma drainage implant tube coverage. J Glaucoma. 2002;11(2):143-147.

21. Raviv T, Greenfield DS, Liebmann JM, Sidoti PA, Ishikawa H, Ritch R. Pericardial patch grafts in glaucoma implant surgery. $J$ Glaucoma. 1998;7(1):27-32.

22. Lankaranian D, Reis R, Henderer JD, Choe S, Moster MR. Comparison of single thickness and double thickness processed pericardium patch graft in glaucoma drainage device surgery: a single surgeon comparison of outcome. J Glaucoma. 2008;17(1):48-51.

23. Trubnik V, Zangalli C, Moster MR, et al. Evaluation of Risk Factors for Glaucoma Drainage Device-related Erosions: A Retrospective Case-Control Study. J Glaucoma. Epub 2013 Dec 10.

24. Byun YS, Lee NY, Park CK. Risk factors of implant exposure outside the conjunctiva after Ahmed glaucoma valve implantation. Jpn J Ophthalmol. 2009;53(2):114-119.

25. Huddleston SM, Feldman RM, Budenz DL, et al. Aqueous shunt exposure: a retrospective review of repair outcome. J Glaucoma. 2013;22(6): 433-438.

26. Koval MS, El Sayyad FF, Bell NP, et al. Risk factors for tube shunt exposure: a matched case-control study. J Ophthalmol. 2013;2013: 196215.

27. Sadik CD, Sezin T, Kim ND. Leukotrienes orchestrating allergic skin inflammation. Exp Dermatol. 2013;22(11):705-709.

28. Lo Schiavo A, Ruocco E, Brancaccio G, Caccavale S, Ruocco V, Wolf R Bullous pemphigoid: etiology, pathogenesis, and inducing factors: facts and controversies. Clin Dermatol. 2013;31(4):391-399.

29. Egrilmez S, Sahin S, Yagci A. The effect of vernal keratoconjunctivitis on clinical outcomes of penetrating keratoplasty for keratoconus. Can J Ophthalmol. 2004;39(7):772-777.
Clinical Ophthalmology

\section{Publish your work in this journal}

Clinical Ophthalmology is an international, peer-reviewed journal covering all subspecialties within ophthalmology. Key topics include: Optometry; Visual science; Pharmacology and drug therapy in eye diseases; Basic Sciences; Primary and Secondary eye care; Patient Safety and Quality of Care Improvements. This journal is indexed on Submit your manuscript here: http://www.dovepress.com/clinical-ophthalmology-journal

\section{Dovepress}

PubMed Central and CAS, and is the official journal of The Society of Clinical Ophthalmology (SCO). The manuscript management system is completely online and includes a very quick and fair peer-review system, which is all easy to use. Visit http://www.dovepress.com/ testimonials.php to read real quotes from published authors. 